\title{
Game Theoretical Approach to Supply Chain Microfinance
}

\author{
Jaehun Sim and Vittaldas V. Prabhu \\ The Harold and Inge Marcus Department of \\ Industrial and Manufacturing Engineering \\ 310 Leonhard Building \\ University Park, PA 16802 \\ Jus238@psu.edu, prabhu@engr.psu.edu
}

\begin{abstract}
This paper considers a supply chain microfinance model in which a manufacturer acts as a lender and a raw material supplier as a borrower. Using a game theoretical analysis, the study investigates how investment levels, raw material prices, and profit margins are influenced by loan interest rates under two types of decentralized channel policies: manufacturer Stackelberg and vertical Nash game. In addition, the study shows how the profits of a manufacturer and a supplier are changed under each supply chain channel structure.
\end{abstract}

Keywords: Game Theory and Supply Chain Microfinance.

\section{Introduction}

Over the past several years, business leaders have realized that economic growth and success can be enhanced by their efforts toward both environment and social values (Stead et al. 2008). This central concept, corporate sustainability, has become a fundamental principle in the search for sustainable competitive advantages for companies (Savitz and Weber, 2006). For example, global leaders such as Shell, Philips, BASF, and Toyota have incorporated this new concept into their business strategies (Ahn et al. 2008).

Since the success of microfinance institutions (MFIs) in the early 1990s, an effective microfinance program can be considered a corporate sustainability approach for alleviating poverty by offering small amount loans with no collateral requirement to the poor in both developing and developed countries. With the objective of empowering the poor to become self-employed, the microfinance program provides the poor with access to financial and social services in the form of credit opportunities, education, health care, insurance, and savings (Sengupta and Aubuchon, 2008).

Despite their flexibility, MFIs experience difficulty in increasing outreach toward their particular clientele and keeping the sustainability of the institutions at the same time. This difficulty can be attributed to several problems, including high levels of poverty and risk, information asymmetries, incentive incompatibilities, and imperfect enforcement mechanisms (Conning and Udry, 2007). Also, due to the unique features 
of microfinance, the interest rate is considered to be an important problem because it does not perfectly represent the lender's opportunity costs of loans nor increase the lender's profits, as in a traditional financial market.

To offer a financial sustainability solution, this study incorporates the concept of supply chain finance and proposes the concept of supply chain microfinance to examine the relationships between investment levels, raw material prices, profit margins, and loan interest rates. The basic idea of supply chain microfinance is that the high creditworthiness of a manufacturer can provide a raw material supplier with the low creditworthiness a loan at a low interest rate.

As shown in Figure 1, supply chain microfinance has three players: a bank, a manufacturer, and a supplier. It is assumed that a poor supplier does not have its own financial resources and has little chance to borrower a loan from the bank in order to invest in a project. Even if the supplier obtains a loan, his or her low credit score leads to a high interest rate.

In the supply chain microfinance environment, the high credit score of a manufacturer attracts an investment from a bank with a low interest rate. In turn, the manufacturer lends to the poor supplier at a low interest rate. When the supplier invests in a project with an investment $I_{M}$ from the manufacturer, the supplier expects a rate of return $R_{P}$ from the project and repay $R_{M}$ to the manufacturer. When the manufacturer invests a supplier's project with an investment $I_{B}$, the manufacturer expects a rate of return $R_{M}$ from the supplier and the intangible benefit of corporate social responsibility $\theta$ and makes a repayment $R_{B}$ to the bank.

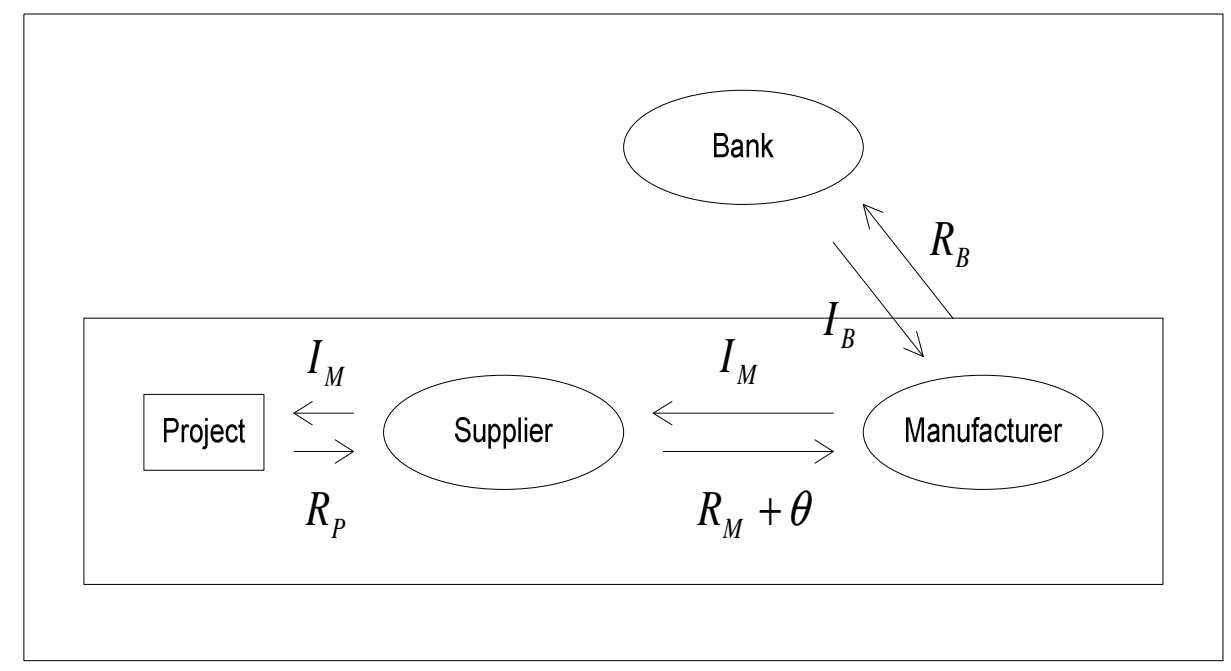

Fig. 1. Basic Model of Supply Chain Microfinance 


\section{Literature Review}

Since the concept of corporate social responsibility has appeared in the early 1960's, corporations have increasingly had to consider environmental and social dimensions as part of their supply chain issues. Despite the growing interest in sustainable supply chain practices, there has not been much research conducted in this regard, compared to conventional supply chain.

Koplin et al. (2007) utilize environmental and social standards at Volkswagen to decrease economic, environmental and social risks throughout the supply chain. Ciliberti et al. (2008) introduce the taxonomy of the logistics social responsibility (LSR) practices based on literature reviews and empirical analysis. Considering a balance between profit and the environment, Fisch and Neo (2008) propose a framework for the design and evaluation of sustainable logistics networks. Guillen and Grossmann (2009) design a sustainable supply chain in the chemical industry under uncertainty in the life cycle inventory.

\section{The Game Model}

This study considers one supplier and one manufacturer under two sub-problems: manufacturer Stackelberg and vertical Nash game. The modeling approach is similar to Ghosh's approach (Ghosh and Shah, 2012). In this decentralized channel policy, it is assumed that the manufacturer makes decisions on the investment level of corporate social responsibility and the profit margin. On the other hand, the supplier makes a decision on the raw material price.

Based on economic theories, a demand function is assumed to have a linear function of a market size $M$, manufacture price $P$, and the investment level of corporate social responsibility $I$. In addition, the product price is the sum of raw material price $s$ and profit margin $m$. The demand function is given as follows.

$$
q=M-\beta P+\alpha I
$$

In this equation, $\alpha$ is the demand coefficient of the corporate social responsibility and $\beta$ is the influence of price fluctuation on demand. It is assumed that the effort of the corporate social responsibility increases the demand by $\alpha I$. In addition, the cost of corporate social responsibility such as fair price is assumed to be $\theta I^{2}$. Based on these assumptions, the manufacture profit and the supplier profit are given as follows.

$$
\begin{gathered}
\Pi_{M}=(m-s-c)(M-\beta(s+m)+\alpha I)+I R_{M}-I R_{B}-\theta I^{2} \\
\Pi_{S}=s(M-\beta(s+m)+\alpha I)+I R_{P}-I R_{M}
\end{gathered}
$$

In these equations, $c$ is a production $\operatorname{cost}, \theta$ is the cost coefficient of corporate social responsibility, $R_{M}$ is an interest rate of a manufacturer, and $R_{B}$ is an interest rate of 
a bank. In the manufacturer Stackelberg, the manufacturer decides the investment level of corporate social responsibility and the product margin in response to the supplier. Then, the supplier decides the raw material price given the investment level and profit margin. In this policy, it is assumed that the manufacturer plays a Stackelberg leader. The optimal investment level, the optimal manufacture margin, the optimal raw material price, and the optimal product price are given as follows.

$$
\begin{gathered}
I^{*}=\frac{M \alpha-c \alpha \beta+3 \alpha^{2} \theta+3 \beta \theta^{2}+3 \beta R_{B}-3 \beta R_{M}}{2 \alpha^{2}} \\
m^{*}=\frac{M \alpha+c \alpha \beta+\alpha^{2} \theta-\beta \theta^{2}-\beta R_{B}+\beta R_{M}}{2 \alpha \beta} \\
s^{*}=-\frac{-M \alpha+c \alpha \beta-\alpha^{2} \theta-2 \beta \theta^{2}-2 \beta R_{B}+2 \beta R_{M}}{2 \alpha \beta} \\
P^{*}=s^{*}+m^{*}=\frac{2 M \alpha+2 \alpha^{2} \theta+\beta \theta^{2}+\beta R_{B}-\beta R_{M}}{2 \alpha \beta}
\end{gathered}
$$

In the vertical Nash game, the supplier chooses the raw material price in response to the investment level and the profit margin, and the manufacturer chooses the investment level and the profit margin in response to the raw material price. In this policy, it is assumed that neither the manufacturer nor the supplier has the power to control the market. The optimal investment level, the optimal profit margin, the optimal raw material price, and the optimal product price are given as follows.

$$
s^{*}=\frac{2 M \theta+2 c \beta \theta+\alpha R_{B}-\alpha R_{M}}{\alpha^{2}-8 \beta \theta}
$$

Substituting the value of $s^{*}$ into the value of $m$, derive

$$
m^{*}=\frac{c \alpha^{2}-4 M \theta-4 c \beta \theta+2 \alpha R_{B}-2 \alpha R_{M}}{\alpha^{2}-8 \beta \theta}
$$

Substituting the value of $s^{*}$ into the value of $I$, derive

$$
I^{*}=\frac{-M \alpha+c \alpha \beta+4 \beta R_{B}-4 \beta R_{M}}{\alpha^{2}-8 \beta \theta}
$$


Thus, the optimal product price is

$$
P^{*}=\frac{2\left(-2 M \theta+2 c \alpha \beta+\alpha R_{B}-\alpha R_{M}\right)}{\alpha^{2}-8 \beta \theta}
$$

\section{$4 \quad$ Result and Discussion}

In this study, the manufacturer Stackelberg and Nash game cases are considered to analyze the impacts of the manufacturer's interest rate. Due to the characteristics of supply chain microfinance, supplier Stackelberg is not considered because the supplier Stackelberg is not reasonable in the microfinance environment in which the manufacturer has more power than the supplier to control the market. For a numerical analysis of manufacturer Stackelberg, the following values are used, $M=200, \alpha$ $=0.2, \beta=0.5, c=6, \theta=3.5, R_{M}=0.2$, and $R_{B}=0.1$.

As shown in Figure 2, the manufacturer's interest rate has a decreasing effect on the investment level of corporate social responsibility. Conversely, the manufacturer's interest rate has an increasing effect on the profit margin.

The manufacturer's interest rate has a decreasing effect on the supplier's raw material price. Similarly, the manufacturer's interest rate has a decreasing effect on the manufacturer's product price. On the other hand, under the Nash game, the numerical analysis indicates that the interest rates of a manufacturer have little impact on corporate social responsibility, the manufacturer's profit margin, or the raw material cost.
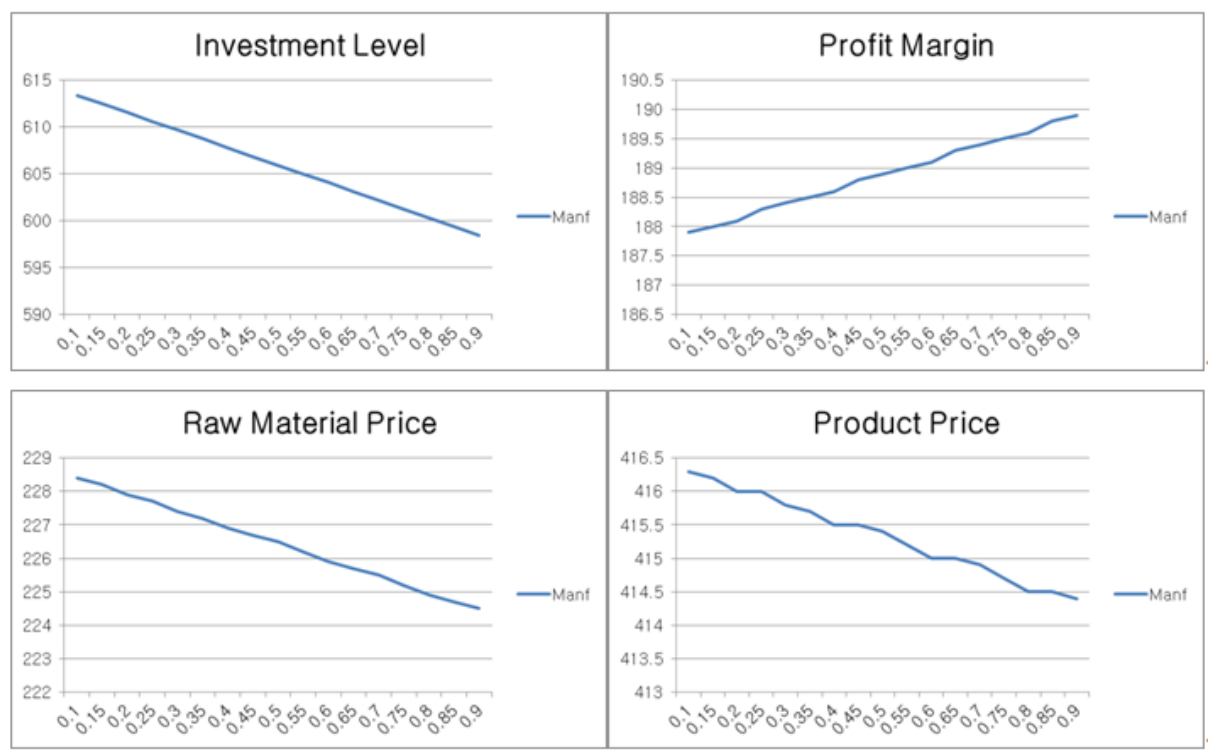

Fig. 2. The Effects of Manufacturer's Interest rates 


\section{Conclusion}

This study investigates the impact of corporate social responsibility on the supply chain microfinance under two decentralized channel policies. The result shows that the manufacturer's interest rate has a positive influence on the manufacturer's margin under manufacturer Stackelberg. In the supply chain microfinance business environment, this study shows that manufacturer Stackelberg is an appropriate model which fully incorporates the characteristics of microfinance. In the future, this study will explicitly model two features; corporate social responsibility and supply risk, to assess how the corporate decreases the supply risk and impacts the sustainable supply chain.

\section{References}

1. Ahn, M.J., Meeks, M.: Building a conducive environment for life science-based entrepreneurship and industry clusters. Journal of Commercial Biotechnology 14(1), 20-30 (2008)

2. Ciliberti, F., Pontrandolfo, P., et al.: Investigating corporate social responsibility in supply chains: A SME perspective. Journal of Cleaner Production 16(15), 1579-1588 (2008)

3. Conning, J., Udry, C.: Rural financial markets in developing countries. Handbook of Agricultural Economics 3, 2857-2908 (2007)

4. Fisch, G.G.J., Neo, T.S.P.: Green automotive supply chain for an emerging market. Massachusetts Institute of Technology (2008)

5. Ghosh, D., Shah, J.: A comparative analysis of greening policies across supply chain structures. International Journal of Production Economics 13, 568-583 (2012)

6. GuillénGosálbez, G., Grossmann, I.E.: Optimal design and planning of sustainable chemical supply chains under uncertainty. AIChE Journal 55(1), 99-121 (2009)

7. Koplin, J., Seuring, S., et al.: Incorporating sustainability into supply manage-ment in the automotive industry-The case of the Volkswagen AG. Journal of Cleaner Production 15(11-12), 1053-1062 (2007)

8. Savitz, A.W., Weber, K.: The triple bottom line: How today's best-run companies are achieving economic, social, and environmental success-and how you can too. Jossey-Bass Inc. Pub. (2006)

9. Sengupta, R., Aubuchon, C.P.: The microfinance revolution: An overview. Federal Reserve Bank of St. Louis Review 90(1), 9-30 (2008)

10. Stead, J.G., Stead, W.E.: Sustainable strategic management: An evolutionary perspective. International Journal of Sustainable Strategic Management 1(1), 62-81 (2008) 